\title{
Ultrasonic assessment of injuries to the lateral complex of the ankle
}

\author{
A. K. SINGH, T. S. MALPASS \& G. WALKER \\ Department of Accident and Emergency, Wycombe General Hospital, High Wycombe, \\ England
}

\section{SUMMARY}

A prospective study of 114 patients who injured the lateral complex of their ankles. AI patients were subjected to ultrasound scanning within $48 \mathrm{~h}$ of their injury under double blind conditions. The authors' results suggest that the sensitivity of the ultrasound diagnosis approaches that of conventional radiology, if used properly. Furthermores, ultrasonic scanning is a useful adjuvant to clinical assessment of patients with regards selection for further radiological examination. A case is also made for firms in the medical physics arena to develop suitable hardware in the diagnostic ultrasonic fieldafiof fracture management.

\section{INTRODUCTION}

That the piezo electric effect of ultrasound causes pain at fracture sites is well know (Oakley, 1978). Furthermore, the use of ultrasound in the therapeutic range has bee investigated by various workers (Shenouda, 1987; Bedford, 1982; Nitz \& Scoville, 1980 in the field of fracture diagnosis with high correlation (93\%) with X-ray findings.

Most of the studies have employed ultrasonic energy at one frequency (approximate $1.5 \mathrm{MHz}$ ) and at therapeutic 'strength levels' $(1 \mathrm{Watt} / \mathrm{sq} \mathrm{cm})$.

The number of X-ray examinations in the A\&E departments is increasing at aboư $6 \%$ per annum without a corresponding increase in the population (Raison, 1976 Ankle radiographs represent $10 \%$ of these examinations.

Certain clinical guidelines have been suggested to help doctors in deciding whethe्p radiographic examination would be useful in an ankle injury (Garfield, 1960; de Lacets 1979) but despite this, fracture diagnosis on clinical grounds alone is notoriouslö inaccurate especially in the hands of inexperienced casualty officers.

Correspondence: Mr A. K. Singh, 16 Hurst Lane, East Molesey, Surrey KT8 9AF, England. 
A simple cost-effective method of supplementing clinical examination is therefore a valuable adjuvant for patient selection regarding possible radiology.

In order to accustomize ourselves with the technique of using ultrasound for fracture management we decided to use the simple diagnostic Doppler Unit for vascular/ obstetric use available in most casualty departments. We found to our surprise that this small unit could produce paraesthesia over fracture sites which correlated very significantly with pain produced over the same sites by ultrasound in the 'therapeutic range'. This parasthesia was even more intense with a modified Doppler unit which delivered $4 \mathrm{~V}$ across the crystal and $250 \mathrm{~mW}$ of power.

\section{METHOD}

The selection criteria for patients entering the study were fairly rigid in that isolated injuries to the lateral complex of the ankle associated with weight-bearing (partial or full) were entered. Patients less than 10 years of age and more than 80 were excluded. Clinical examination of the injured part was followed by a quick Doppler ultrasonic examination of the injured ankle (control-normal ankle) and by routine radiology of the affected part. The patient was then sent down to the Physiotherapy Department for an ultrasound test on both ankles using ultrasound at 1.5 watts $/ \mathrm{sq} \mathrm{cm}$ and 1.5 and $3 \mathrm{MHz}$ frequencies.

The initial Doppler evaluation was performed at two frequency levels, ie. $2 \mathrm{MHz}$ and $5 \mathrm{MHz}$, the examining doctor being unaware of the radiological findings. Similarly the testing physiotherapist was completely unaware of both the radiological and the Doppler findings.

Ultrasonic diagnosis was carried out by a single Senior Physiotherapist using a standard therapeutic ultrasound machine and a water-based coupling medium. The probe diameter was $0.75 \mathrm{~cm}$. The sensation produced was compared to that obtained on the same area of the opposite, uninjured limb. A positive test was pain/paraesthesia over the injured limb only.

Patients with a positive ultrasound examination and negative radiology initially, were followed up and repeat X-rays performed 3 weeks later.

A total of 114 patients were examined.

\section{RESULTS}

On reviewing radiographs after the application of the diagnostic Doppler ultrasound it was found that 23 patients had sustained fractures around the lateral complex. Subsequent repeat radiology in those patients with an initially negative $\mathrm{X}$-ray finding, but positive ultrasound testing, revealed the presence of four additional fractures. These included flake fractures of the dorsum of the talus, minor chip avulsions of the tip of the lateral malleolus, fracture of the talar neck and a fracture of the base of the fifth metatarsal. Fractures distal to the ankle were missed as views of the foot/talus were not 
initially requested. These patients were, however, included in the trial as it was felt that precisely these patients would have been helped by a positive ultrasonic scanning initially.

It is felt that a positive result to an ultrasound test (in the absence of radiologicall evidence of a fracture in the available views) would increase the index of suspicion in the attending doctor's mind and therefore prompt him to request additional views.

The results are summarized in Tables 1 and 2 . Similarly using both modalities of ultrasonic examination together and comparing them to the overall efficacy of radiolog cal examination, we found a $\chi^{2}$ value of $45 \cdot 7$.

Further statistical analysis of the results is given in Table 3. To our surprise we found that patients under the age of 55 were more likely to have sustained injuries to the lateral complex of their ankles as compared to those above that age limit $\left(\chi^{2}=11 \cdot 8\right)$.

Table $1 \quad \chi^{2}$ matrices

\begin{tabular}{|c|c|c|c|}
\hline & $\begin{array}{l}\text { Therapeutic } \\
\text { U/s positive }\end{array}$ & $\begin{array}{l}\text { Therapeutic } \\
\mathrm{U} / \mathrm{s} \text { negative }\end{array}$ & Total \\
\hline $\begin{array}{l}X \text {-ray Positive } \\
\text { X-ray Negative } \\
\text { Total } \\
\chi^{2}=43.3\end{array}$ & $\begin{array}{l}21 \\
12 \\
33\end{array}$ & $\begin{array}{r}5 \\
76 \\
81\end{array}$ & $\begin{array}{r}26 \\
88 \\
114\end{array}$ \\
\hline & $\begin{array}{c}\text { Doppler } \\
\text { U/s Positive }\end{array}$ & $\begin{array}{c}\text { Doppler } \\
\text { U/s Negative }\end{array}$ & Total \\
\hline X-ray Positive & 17 & 7 & 24 \\
\hline $\mathrm{X}$-ray Negative & 10 & 80 & 90 \\
\hline $\begin{array}{l}\text { Total } \\
\chi^{2}=37 \cdot 3\end{array}$ & 27 & 87 & 114 \\
\hline
\end{tabular}

Table 3

\begin{tabular}{|c|c|c|c|c|}
\hline Test & Sensitivity & $\begin{array}{l}\text { False } \\
\text { Pos. }\end{array}$ & Specificity & $\begin{array}{l}\text { False } \\
\text { Neg. }\end{array}$ \\
\hline X-ray & $85 \cdot 2 \%$ & 0 & $100 \%$ & $14 \cdot 8 \%$ \\
\hline Both U/s & $88.9 \%$ & $6.9 \%$ & $93 \cdot 1 \%$ & $11 \cdot 1 \%$ \\
\hline Doppler & $70 \cdot 8 \%$ & $11 \cdot 1 \%$ & $88.9 \%$ & $29 \cdot 2 \%$ \\
\hline Therap. U/s. & $80 \cdot 8 \%$ & $13.6 \%$ & $86.4 \%$ & $19 \cdot 2 \%$ \\
\hline $\mathrm{X}$-rays and both $\mathrm{U} / \mathrm{s}$ & $96.4 \%$ & - & - & $3.6 \%$ \\
\hline
\end{tabular}


Furthermore, we found that physical parameters such as swelling over the lateral complex, weight-bearing and time of presentation were completely independent of the radiological findings. However, we found a positive correlation between bony tenderness and the presence of a fracture $\left(\chi^{2}=7 \cdot 5\right)$.

One of the parameters that we recorded for every patient was the time of presentation to the A\&E Department. We found that there was no significant correlation between this time of presentation and the sex or age of the patient. Surprisingly, we also found no correlation between this parameter and the patient's ability to weight-bear or the presence radiologically of a fracture.

Using the different ultrasonic frequencies available $(1.5,2.3$ and $5 \mathrm{MHz}$ ) we found that at the level of therapeutic use of ultrasound, ie. $1 \mathrm{~W} / \mathrm{sq} \mathrm{cm}$, the $1.5 \mathrm{MHz}$ frequency was most effective as compared to the $5 \mathrm{MHz}$ frequency at the Doppler level (50250 mWatts).

We subsequently modified our Doppler ultrasound unit to deliver a 4-V potential difference across the crystal surface and thereby quadrupling the available power output. We have found this to be even more effective and sensitive in diagnosing bony injuries around the ankle.

\section{DISCUSSION}

This study suggests that ultrasound is a simple, inexpensive and diagnostically effective method for detecting bony injuries to the lateral complex of the ankle. Twenty-four of the 27 bony injuries were detected using both modalities of ultrasound giving an overall sensitivity of $\mathbf{8 8 . 9 \%}$ as compared to $\mathbf{8 5 . 2 \%}$ for routine radiology.

However, when both routine radiology and ultrasound scanning were performed, the overall sensitivity increased to $96 \cdot 4 \%$ with a false negative rate of $3.6 \%$.

It is interesting to note that only one out of the 27 fractures in the study was not picked up by either X-ray or ultrasonic scanning. This turned out to be a minor flake avulsion of the tip of the lateral malleolus in a diabetic patient with peripheral neuropathy. We feel, in retrospect, that our false negative rate would have been negligible had she been excluded from the trial due to the diminished sensation in her foot.

When Doppler ultrasonic examination was used in isolation however, this sensitivity dropped to $70 \cdot 8 \%$, there being a significant false negative rate of $29 \cdot 2 \%(80.8 \%$ sensitivity and $19.2 \%$ false negative rate being achieved for Ultrasound in the Therapeutic range in isolation.)

It is therefore felt that simple Doppler examination of minor ankle injuries along with reasonably precise clinical examination would result in far more accurate assessment of these injuries regarding the necessity for subsequent radiological examination. It is not suggested by us that routine ultrasonic examination of injuries would replace radiological assessment; rather that when used properly could enable relatively inexperienced doctors to assess the requirements for X-rays more precisely and accurately.

An additional value of ultrasonic assessment is that in the absence of a detectable fracture in the $\mathrm{X}$-rayed region, a positive ultrasound result should raise the doubt of a fracture in a contiguous anatomical area. 
We feel that a strong case exists for firms in the diagnostic ultrasound sector to stud further the effect of different parameters such as frequency, optimal strength/unit area crystal size and head profile etc., so that in time an optimal portable diagnostie instrument is made available for most A\&E departments to use.

\section{REFERENCES}

Bedford A. F., Glasgow M. \& Wilson J. N. (1982) Ultrasonic assessment of fractures and its use in the diagnosis of the suspected scaphoid. Injury, 2, 180-2.

De Lacey G. J., Bradbrooke S. (1979) Rationalizing requests for X-ray examination of acute ankle injuries $\overrightarrow{0}$ British Medical fournal 1, 1597-8.

Garfield J. S. (1960) Is radiological examination of the twisted ankle necessary? Lancet ii, $1167-69$.

Nitz A. J. \& Scoville C. R. (1980) Use of ultrasound in early detection of stress fractures of the medial tibiak plateau. Military Medicine 145, 844-6.

Oakley E. M. (1978) Dangers and contraindications of therapeutic ultrasound. Physiotherapy 64, $173-9$.

Raison J. C. A. (1976) Proceedings of the Royal College of Medicine 69, 755.

Shenouda N. A. \& England J. P. S. (1987) Ultrasound in the diagnosis of scaphoid fractures. Fournal of Han $\$$ Surgery 12b, 43-5. 